\title{
Clinical efficacy of estradiol transdermal system in the treatment of hot flashes in postmenopausal women
}

This article was published in the following Dove Press journal:

Research and Reports in Transdermal Drug Delivery

I July 2014

Number of times this article has been viewed

\author{
Camil Castelo-Branco' \\ Iris Soveral ${ }^{2}$ \\ 'Institute of Gynecology, Obstetrics \\ and Neonatology, Faculty of Medicine, \\ University of Barcelona, Hospital \\ Clinic, Institut d'Investigacions \\ Biomèdiques August $\mathrm{Pi}$ i Sunyer, \\ ${ }^{2}$ Institute of Gynecology, Obstetrics \\ and Neonatology, Faculty of Medicine, \\ University of Barcelona, Hospital \\ Clinic, Barcelona, Spain
}

\begin{abstract}
Hot flashes are among the most common symptoms of estrogen deprivation associated with menopause. Hot flashes affect quality of life in menopausal women and constitute the main indication for hormonal replacement. Treatment using estrogens with or without a progestin is highly effective in reducing the frequency and intensity of hot flashes. There are several estrogen formulations available for the treatment of menopausal symptoms, including oral, transdermal, intranasal, and vaginal preparations. Within the transdermal group, several preparations exist and all have been shown to be effective in the control of hot flashes. Transdermal estrogens constitute an effective treatment for menopausal hot flashes and may have additional beneficial effects compared with oral treatment, given that first-pass hepatic metabolism is avoided using the transdermal route. Transdermal estrogens should be considered as a viable treatment option for symptomatic menopausal women. When it has been decided to use the transdermal route, the woman should be informed of the benefits and side effects of each transdermal system and her preference taken into account when recommending a specific transdermal preparation.
\end{abstract}

Keywords: menopause, hormone therapy, transdermal, vasomotor symptoms

\section{Introduction}

The menopausal transition and the postmenopausal period are associated with a variety of symptoms associated with estrogen deprivation. ${ }^{1,2}$ Among these, hot flashes are the most common, affecting approximately $80 \%$ of women ${ }^{3}$ during the menopausal transition. Hot flashes are described as a sudden transient sensation of intense heat, sweating, clamminess, flushing, and chills. Hot flashes are accompanied by peripheral vasodilatation, an increase in skin temperature and blood flow, and increased sweating. ${ }^{2}$ The origin of hot flashes is clearly associated with estrogen deprivation. However, no correlation has been found between the occurrence of hot flashes and plasma or urinary levels of estrogen. ${ }^{1,4}$ Moreover, no differences in estrogen levels have been found between symptomatic and asymptomatic women. ${ }^{5,6}$ Therefore, other factors must be involved in determining why some women experience hot flashes and others do not. Although the etiology of hot flashes remains unknown, it has been proposed that they are caused by a dysfunction of hypothalamic thermoregulation secondary to estrogen deprivation. ${ }^{2,7}$ The thermoneutral zone seems to be narrower in postmenopausal women, and small increases in core body temperature can trigger the heat dissipation response, ie, hot flashes (peripheral vasodilatation and sweating)..$^{5}$ Therefore, the efficacy of estrogen therapy in the management of hot flashes could be related to a widening of this thermoneutral zone and an increased core temperature threshold for heat dissipation responses. Hot flashes can be highly disruptive to daily life in menopausal women
Correspondence: Camil Castelo-Branco Institute of Gynecology, Obstetrics and Neonatology, Hospital Clínic, Villarroel 170, 08036, Barcelona, Spain Email castelobranco@ub.edu submit your manuscript $\mid$ www.dovepress.com

Dovepress

http://dx.doi.org/1 0.2147/RRTD.S47532
Research and Reports in Transdermal Drug Delivery 2014:3 I-8

(c) (i) (5) 2014 Castelo-Branco and Soveral. This work is published by Dove Medical Press Limited, and licensed under Creative Commons Attribution - Non Commercial (unported, v3.0) permission from Dove Medical Press Limited, provided the work is properly attributed. Permissions beyond the scope of the License are administered by Dove Medical Press Limited. Information on permission from Dove Medical Press Limited, provided the work is properly attributed.
how to request permission may be found at: http://www.dovepress.com/permissions.php 
and can also affect sleep quality. The presence of hot flashes and their negative impact on quality of life constitute the main indication for estrogen replacement in the menopausal period. Estrogen therapy with or without a progestin is highly effective in reducing the frequency and intensity of hot flashes and constitutes the standard of care for treatment of these women. ${ }^{8}$ Treatment with estrogens should be maintained using the lowest possible dose necessary for symptom control and for the shortest period of time possible. ${ }^{9}$

Several estrogen preparations have developed for the treatment of menopausal symptoms, including oral, transdermal, intranasal, and vaginal formulations. The oral route (the first developed) has been the reference point for comparison when other delivery systems have become available. The transdermal and intranasal routes both avoid hepatic first-pass metabolism and its consequences, which may constitute an advantage. Nowadays, the transdermal route is the main alternative to the oral preparations given that the intranasal delivery system, despite its effectiveness, had a clear economic disadvantage and is no longer commercially available. ${ }^{10}$ Finally, the vaginal route is adequate for treatment of vaginal and pelvic symptoms, but is not useful in the treatment of other menopausal symptoms, such as hot flashes. This review focuses on the efficacy of transdermal estrogen delivery for the clinical management of hot flashes.

\section{Methods}

A systematic review was carried out using studies involving transdermal estrogens for the treatment of hot flashes. To identify papers describing a relationship between treatment with transdermal estrogens and hot flashes, the following keyword-based search strategy was designed: (hot flashes OR hot flushes OR vasomotor symptoms) AND (menopause) AND (transdermal estrogen). This strategy was adapted and

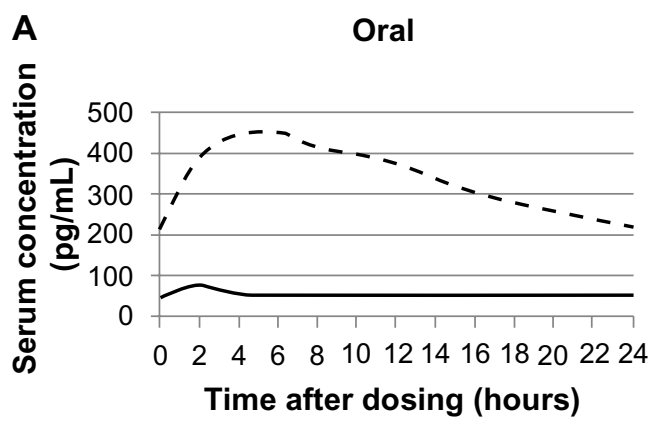

applied to several widely used Internet search engines, to the MEDLINE database (1966 to November 2013), and to the Cochrane Controlled Trials Register. There was no language or date restriction. This search was further supplemented by handsearching of the reference lists of selected review papers.

\section{Transdermal estradiol delivery systems: characteristics and pharmacokinetics}

Estradiol is a small lipophilic molecule and this characteristic has facilitated the development of transdermal estradiol delivery systems. Transdermal drug delivery technology has progressed since its initial development in 1979. Transdermal delivery of estradiol is now available using patches (reservoir, matrix, and delivery-optimized thermodynamic matrix technology) and other preparations including gel, emulsion, and spray formulations. These systems are explained further below. Other transdermal drug delivery technologies are currently in development to overcome the present limitations of skin diffusion. Microneedles and thermal ablation are the most promising technologies. They allow for transdermal delivery of molecules that are far larger than estradiol and, in the future, might become additional options for transdermal estradiol delivery. ${ }^{11}$

The main pharmacokinetic feature of the transdermal delivery systems in comparison with oral estradiol is avoidance of first-pass hepatic metabolism. Together with the low bioavailability of oral estrogen, ${ }^{12}$ bypass of first hepatic metabolism results in lower doses being needed to achieve similar plasma concentrations. As a result of the lack of intestinal and first-pass hepatic metabolism, a different profile of intermediate metabolites is seen. ${ }^{13}$ Specifically, the estrone to estradiol ratio is closer to 1:1 with the transdermal route, which mimics the physiologic ratio seen in premenopausal women. ${ }^{14-16}$ These effects are summarized in Figure 1.

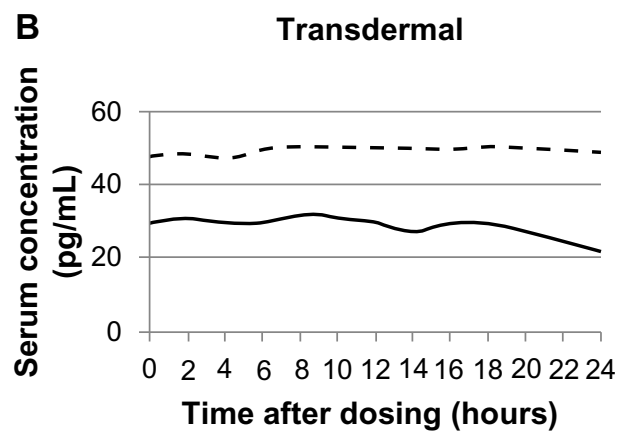

Figure I Differences in plasma concentrations of estradiol and estrone after administration of oral versus transdermal estrogens in healthy postmenopausal women. Notes: (A) Mean plasma estradiol and estrone concentrations after multiple doses of oral estradiol (I mg/day). Adapted from Femtrace ${ }^{\circledR}$ Prescribing Information. Rockaway, NJ, USA: Warner Chilcott, LLC.; December 2009. Available from http://www.drugs.com/pro/femtrace.html. ${ }^{15}$ (B) Mean plasma concentrations of estradiol and estrone after multiple applications of estradiol gel $\left(0.75 \mathrm{mg} /\right.$ day). Adapted from EstroGel ${ }^{\mathrm{TM}}$ Prescribing Information. San Antonio, TX, USA: Ascend Therapeutics, Inc.; 2012 . Available from: http://files.estrogel.gethifi.com/EstroGel_PI_Nov_09_C980.pdf. ${ }^{16}$ 
The hepatic first-pass implies other physiologic effects. For example, the effect of estradiol on the serum concentration of insulin-like growth factor 1 depends on the route of estradiol administration. Oral estradiol intake results in a decreased serum concentration of this protein but no concentration change is seen with transdermal estradiol. The clinical significance of this fact remains uncertain. ${ }^{17} \mathrm{Also}$, oral estrogens are associated with an increase in the synthesis of some coagulation factors, that might play a role in the increased risk of thromboembolism described with oral estrogens. ${ }^{18,19}$ Another characteristic of the transdermal route is that it maintains relatively stable concentrations of estradiol, resembling the physiologic levels found before menopause. However, this plateau in estrogen levels does not seem to be necessary for adequate treatment of hot flashes. ${ }^{10,20}$ Figure 2 shows the similarities in the different transdermal estrogen delivery systems (patch, gel, and spray) with regard to maintenance of relatively stable concentrations of estradiol ${ }^{21,22}$ and draws comparisons with oral estradiol (Figure 3).

\section{Estradiol patches}

The first transdermal delivery system developed was the reservoir patch, which consisted of an estrogen reservoir with an alcohol-containing membrane that enables stable release of estrogen. ${ }^{23}$ The adhesive completely covers the bottom layer of the patch which, together with the alcohol-containing membrane, has been associated with skin reactions that may limit the acceptance of this type of patch..$^{24-26}$

Matrix patches were the next to be developed, and consist of a single layer containing a mixture of the active ingredient within a polymer or plastic tissue and an adhesive in direct contact with the skin and without the need for a ratecontrolling membrane. ${ }^{24}$ Accordingly, fewer skin reactions are reported with this type of patch. ${ }^{27}$

Finally, technological improvements in matrix delivery systems have allowed the development of smaller patches providing doses similar to those delivered by other matrix patches via improved dispersion of the drug within the acrylic-based adhesive, ie, delivery-optimized thermodynamic matrix technology. ${ }^{28}$

There are many transdermal patches available commercially, with a wide range of dosing options (0.025-0.1 mg/day), and some are available in combination with progestin, making transdermal patches a versatile therapeutic option for the treatment of hot flashes. Local skin reactions are less common with the matrix patches which, together with a
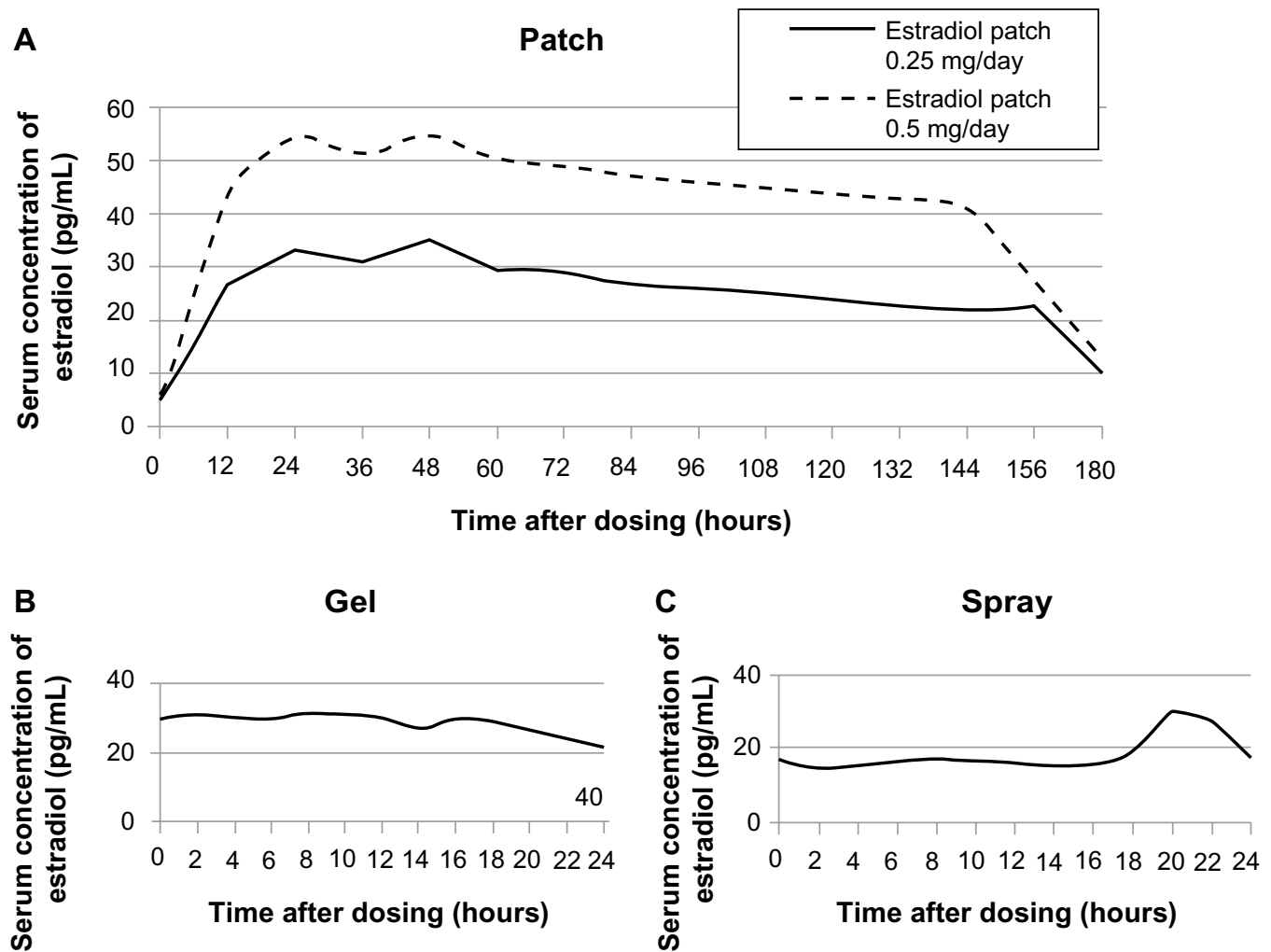

Figure 2 Mean plasma estradiol concentration in healthy postmenopausal women treated for hot flashes using different transdermal estrogen delivery systems. Notes: (A) Mean plasma concentration of estradiol $(\mathrm{pg} / \mathrm{mL})$ over 7 days of estradiol patch use $(0.25 \mathrm{mg} /$ day and $0.5 \mathrm{mg} /$ day). (B) Mean plasma concentration of estradiol $(\mathrm{pg} / \mathrm{mL})$ after application of multiple doses of estradiol gel ( $0.75 \mathrm{mg} /$ day). Adapted from EstroGel ${ }^{\mathrm{TM}}$ Prescribing Information. San Antonio, TX, USA: Ascend Therapeutics, Inc.; 2012 . Available from: http://files.estrogel.gethifi.com/EstroGel_PI_Nov_09_C980.pdf. ${ }^{16}$ (C) Mean plasma concentration of estadiol after I.53mg/day estradiol dose application by transdermal route (spray). Reproduced from Evamist ${ }^{\mathrm{TM}}$ Prescribing Information. St Louis, MO, USA: Ther-RX Corporation; 20I3. Available from: http://www.evamist.com/pdf/Evamist_PI.pdf. ${ }^{22}$ 


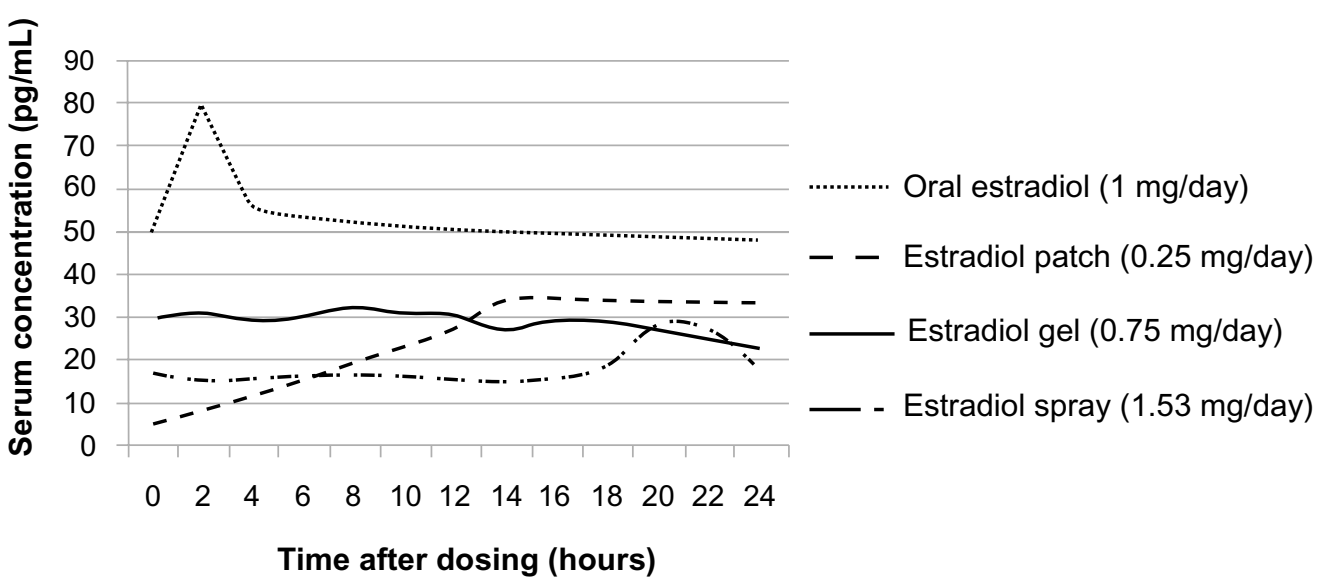

Figure 3 Mean estradiol plasma concentrations in healthy postmenopausal women treated for hot flashes using oral or transdermal estrogen delivery systems. ${ }^{15,16,22}$

once-weekly or twice-weekly dosing regimen, may improve compliance over oral therapy and in comparison with reservoir patches. Despite this, skin reactions still develop and may limit compliance. Further, some women may not consider twice-weekly administration a significant improvement over daily administration.

It has been suggested that some women might be opposed to the visual appearance of the transdermal patches, but the availability of transparent patches might circumvent this problem. ${ }^{26}$ Additionally, transdermal patches may detach prematurely, especially in hot and wet climates, so patches, especially reservoir systems, might not be appropriate for women living in tropical regions. ${ }^{29}$

\section{Estradiol gel, emulsion, and spray formulations}

Alternative transdermal estradiol delivery systems with fewer local side effects have been developed. These include gel, emulsion, and spray preparations. Estradiol emulsion is a lotion-like preparation containing micellar nanoparticles of $17 \beta$-estradiol. When applied to the skin, these micellar nanoparticles are deposited in the outer layers of the skin, creating an estradiol depot that gradually diffuses into the deeper layers and then to the bloodstream. The micellar nanoparticles are created using a mixture of oil, surfactant, water, and alcohol. Sustained therapeutic levels are achieved after the second week of treatment, with a pharmacokinetic profile showing no major fluctuations..$^{30}$ This product is available in individual pouches delivering $8.6 \mathrm{mg}$ of estradiol per pouch. The emulsion is applied to the thigh or calf of both legs until absorption is complete.

Topical estradiol gels are hydroalcoholic and deliver $17 \beta$-estradiol after application to the arms or legs (2-3 minutes' friction). ${ }^{31,32}$ There are multiple dosages available (0.25-1 mg estradiol) and some products allow for dose titration by means of a pump that delivers a fixed amount of gel. Like the emulsion, the product must be allowed to dry before dressing to prevent transfer of estradiol to clothing. Care must also be taken to avoid transfer of estradiol to others, ${ }^{26}$ so contact with the application site must be avoided for 1-2 hours. Also, the skin must be kept dry after application in order to maintain estradiol absorption.

Another percutaneous delivery system is an estradiol transdermal spray that is applied to the upper forearm. The formulation includes estradiol, octisalate, and alcohol, and delivers $1.53 \mathrm{mg}$ of estradiol per pump actuation. The spray dries in approximately one minute and the application area can be touched by others or washed 30 minutes after dosing. ${ }^{33}$ Both these characteristics represent a potential benefit in comparison with estradiol emulsion and gel.

\section{Efficacy of transdermal estradiol in treatment of hot flashes}

Studies assessing the efficacy of transdermal estradiol in the treatment of hot flashes have mostly evaluated the differences in frequency and/or severity of hot flashes from baseline as reported by study participants. No objective or clinically useful tool for measurement of hot flashes is available, and as such, the response to treatment is usually assessed by patients' reports, which makes comparison between studies difficult. However, since the main goal of treating symptomatic women is to improve their quality of life by reducing the frequency and/or intensity of hot flashes, such subjective assessment is clinically relevant. Although most trials include patients with moderate to severe hot flashes, the number of hot flashes necessary for such classification is not the same across the different studies. ${ }^{34}$ Most of the published research is in the form of 
randomized controlled trials, either with placebo and/or another source of estrogens, with a considerable number of participants per group.

The first studies of the efficacy of transdermal estradiol in the treatment of hot flashes were performed comparing the transdermal estradiol patch $(0.02-0.1 \mathrm{mg}$ /day, reservoir or matrix) with either placebo ${ }^{35-39}$ or oral conjugated equine estrogens $^{35,40,41}$ (0.625 mg/day or $1.25 \mathrm{mg} /$ day $)$. These early randomized placebo-controlled studies reported a significant reduction in the frequency and severity of hot flashes in comparison with placebo. The clinical improvement seen in these patients was significant after the second week of treatment and was maintained over a follow-up of 12 weeks. The frequency of hot flashes was reduced in up to $84 \%$ of cases $^{38}$ using doses as low as $0.025 \mathrm{mg} /$ day. ${ }^{39}$ There were no significant differences between patients treated with oral estrogens and those treated with the transdermal estradiol patch, and both formulations were effective in the treatment of hot flashes. ${ }^{35,40,41}$ Therefore, $0.05 \mathrm{mg} /$ day of transdermal estradiol seems to be equivalent to $0.625 \mathrm{mg} /$ day of oral conjugated equine estrogens. In one study, clinical assessment at week 4 found that oral conjugated equine estrogens $(0.625 \mathrm{mg}$ /day) achieved improvement earlier than the transdermal estradiol patch ( $0.05 \mathrm{mg} /$ day), but both groups showed similar clinical responses at 12 weeks. $^{40}$

Common side effects, including breast tenderness and breakthrough bleeding, seem more related to the dosage of estrogen than route of administration. ${ }^{35,40,41}$ Skin tolerability was generally good, but was the reason for withdrawal in up to $8 \%$ of patients during 12 weeks of follow-up. ${ }^{35}$ However, a trial conducted for one year described a $22 \%$ withdrawal rate due to cutaneous side effects in a transdermal matrix patch group and a 50\% withdrawal rate in a reservoir patch group. ${ }^{29}$ This difference might be explained by the longer follow-up in the latter study, or might be secondary to the different climate setting (the latter study was performed in India whereas the other studies were conducted in North America or Europe).

Abnormal bleeding is also a common reason for withdrawal; however, the fact that unopposed estrogen was administered to non-hysterectomized women in most of these studies must be taken into account. The few trials in which a progestin was also administered reported similar results in terms of efficacy, with transdermal estrogen plus progestin being significantly more effective than placebo in the treatment of hot flashes. ${ }^{42-44}$ The adverse effect profile was also similar to that in previous studies, with abnormal bleeding being reported in a few cases. As expected, the results of a meta-analysis of trials comparing transdermal estradiol with placebo favored treatment with transdermal estradiol versus no treatment. ${ }^{34}$

Estradiol emulsion was compared with placebo in a randomized 12-week trial, with the results favoring treatment. The emulsion was effective in reducing hot flashes after the third week of treatment and this effect was maintained throughout follow-up. The emulsion was generally well tolerated with few side effects, including skin reactions. ${ }^{30}$

Estradiol gel has also been superior to placebo in the treatment of hot flashes in randomized placebo-controlled trials. ${ }^{31,45-48}$ The lowest dose of estradiol necessary to achieve a clinical effect was $0.75 \mathrm{mg}$ /day, and this dose was not associated with abnormal bleeding. Higher dosages $(1.5 \mathrm{mg} /$ day) did not significantly improve the response rate compared with $0.75 \mathrm{mg} /$ day, but side effects were more common in the higher dosing group. ${ }^{45}$ Another study showed that induction treatment with estradiol gel $(1.08 \mathrm{mg} /$ day $)$ for 8 weeks followed by maintenance treatment at half-dose ( $0.54 \mathrm{mg} /$ day) can be effective in patients responding to induction treatment. ${ }^{48}$ This suggests that it might be possible to lower the daily dose of estradiol after a clinical response is achieved, thus reducing the risk of adverse effects related to estradiol therapy. ${ }^{48}$

When the gel formulation $(0.1 \mathrm{mg} /$ day $)$ was compared with a matrix patch $(0.05 \mathrm{mg} /$ day $)$, both were equally effective in reducing hot flashes during 12 months of follow-up. ${ }^{49}$ Treatment acceptability was high in both groups, although complaints of skin irritation were more common in the patch group. The outcomes of treatment with estradiol gel were also comparable with those of oral estradiol in a 2-year, randomized, open-label, comparative study. ${ }^{50}$

Finally, the effect of treatment of hot flashes using estradiol spray was assessed in a randomized placebo-controlled trial. Women were randomized to receive one, two, or three sprays daily (1.53 mg per spray) or placebo. The frequency of hot flashes was significantly reduced in the treatment groups compared with placebo, but the decrease in symptoms was not proportional to the number of sprays administered. The frequency of cutaneous reactions at the application site was very low $(1.7 \%) .^{33}$

\section{Other effects of transdermal estrogen therapy}

Transdermal estradiol has been shown to increase bone mineral density (BMD) at the spine and hip. ${ }^{51,52}$ In randomized controlled trials, the effects of estradiol gel on 
BMD were similar to those of oral estrogen. ${ }^{51,53}$ Although this is a beneficial side effect, estrogen therapy is not recommended for prevention of osteoporosis.

Exogenous estradiol affects the endometrium, stimulating its growth regardless of the delivery system used.$^{54}$ However, it seems that the transdermal routes do so to a lesser extent, which is probably due to the lower plasma levels necessary for symptom control. ${ }^{35,40,41}$ Nonetheless, a progestin should always be administered simultaneously in women with an intact uterus, given that this practice has been shown to reduce the risk of endometrial cancer associated with unopposed estrogen therapy. ${ }^{55-58}$

Estrogen has been shown to affect cardiovascular risk factors, such as lipid levels. ${ }^{26,59}$ Oral and transdermal preparations containing estradiol increase high-density lipoprotein levels and decrease low-density lipoprotein and total cholesterol levels in postmenopausal women, and to some extent prevent the lipid profile changes seen after menopause. ${ }^{60,61}$ However, this change in lipid profile does not seem to prevent cardiovascular events in women treated with estrogens. ${ }^{62,63}$ Further, transdermal estradiol seems to have a neutral effect on triglycerides, as opposed to oral estrogens, which seem to increase them. ${ }^{33,64,65}$

Oral estrogen therapy has been associated with an increased risk of venous thromboembolism, which is probably related to the increased synthesis of certain coagulation factors. ${ }^{19,62,65-68}$ However, in case-control studies, women treated with transdermal estrogens did not have an increased risk of thromboembolism as opposed to women receiving oral therapy. ${ }^{66,68}$ However, prospective, long-term randomized trials are necessary to investigate this association further.

\section{Conclusion}

Transdermal systems for delivery of estradiol are as effective as oral estrogens in the treatment of hot flashes, and lower doses seem to be possible. As such, they can be considered as a therapeutic option in symptomatic postmenopausal women. Given the absence of first-pass hepatic metabolism and the minor impact on lipid and coagulation system, the transdermal route could be particularly suitable for women with venous thromboembolism and/or increased cardiovascular risk, hypertriglyceridemia, or cholelithiasis. Although it seems that treatment with transdermal estrogens is associated with a lower endometrial risk than treatment with oral estrogens, a progestin should always be given to women with an intact uterus. This might be an inconvenience in terms of compliance, given that women might prefer two tablets (or one tablet containing a combination of estrogen and progestin) over a patch and tablet (although combined patches are available) or a progestin tablet plus gel, emulsion, or spray (where no combined presentations exist). However, the transdermal route (all types) is generally well accepted and compliance is generally good, except in users of the reservoir patch. In conclusion, transdermal estrogens constitute an effective treatment for menopausal hot flashes and may have additional beneficial effects compared with oral treatment, so should be considered as a viable option in the treatment of symptomatic menopausal women. When the transdermal route has been chosen, women should be informed of the benefits and side effects of each transdermal system and their preference taken into account when recommending a specific transdermal system.

\section{Disclosure}

The authors report no conflicts of interest in this work.

\section{References}

1. Aksel S, Schomberg DW, Tyrey L, Hammond CB. Vasomotor symptoms, serum estrogens, and gonadotropin levels in surgical menopause. Am J Obstet Gynecol. 1976;126:165-169.

2. Freedman RR. Pathophysiology and treatment of menopausal hot flashes. Semin Reprod Med. 2005;23:117-125.

3. Williams RE, Kalilani L, DiBenedetti DB, et al. Frequency and severity of vasomotor symptoms among peri- and postmenopausal women in the United States. Climacteric. 2008;11:32-43.

4. Stone SC, Mickal A, Rye F, Rye PH. Postmenopausal symptomatology, maturation index, and plasma estrogen levels. Obstet Gynecol. 1975;45: 625-627.

5. Freedman RR, Norton D, Woodward S, Cornelissen G. Core body temperature and circadian rhythm of hot flashes in menopausal women. J Clin Endocrinol Metab. 1995;80:2354-2358.

6. Hutton JD, Jacobs HS, Murray MAF, James VHT. Relation between plasma oestrone and oestradiol and climacteric symptoms. Lancet. 1978;1:678-681.

7. Casper RF, Yen SS. Neuroendocrinology of menopausal flushes: an hypothesis of flush mechanism. Clin Endocrinol (Oxf). 1985;22: 293-312.

8. MacLennan AH, Broadbent JL, Lester S, Moore V. Oral oestrogen and combined oestrogen/progestogen therapy versus placebo for hot flushes. Cochrane Database Syst Rev. 2004;4:CD002978.

9. North American Menopause Society. The 2012 hormone therapy position statement of: The North American Menopause Society. Menopause. 2012;19:257-271.

10. Castelo-Branco C, Coloma JL. The role of intranasal estradiol spray in the management of moderate to severe vasomotor symptoms in menopausal women. Gynecol Endocrinol. 2010;26:23-29.

11. Prausnitz MR, Langer R. Transdermal drug delivery. Nat Biotechnol. 2008;26:1261-1268.

12. O'Connell MB. Pharmacokinetic and pharmacologic variation between different estrogen products. J Clin Pharmacol. 1995; 35(Suppl 9):18S-24S

13. Voican A, Francou B, Novac L, et al. Pharmacology of Hormone Replacement Therapy in Menopause. InTech; 2012. Available from: http://www.intechopen.com/download/get/type/pdfs/id/32132. Accessed January 16, 2013.

14. Kuhl H. Pharmacology of estrogens and progestogens: influence of different routes of administration. Climacteric. 2005;8 Suppl 1:3-63. 
15. Femtrace ${ }^{\circledR}$ Prescribing Information. Rockaway, NJ, USA: Warner Chilcott, LLC; 2009. Available from: http://www.drugs.com/pro/ femtrace.html. Accessed November 24, 2013.

16. EstroGel ${ }^{\mathrm{TM}}$ Prescribing Information. San Antonio, TX, USA: Ascend Therapeutics, Inc.; 2012. Available from: http://files.estrogel. gethifi.com/EstroGel_PI_Nov_09_C980.pdf. Accessed November 3, 2013.

17. Sonnet E, Lacut K, Roudaut N, Mottier D, Kerlan V, Oger E. Effects of the route of oestrogen administration on IGF-1 and IGFBP-3 in healthy postmenopausal women: results from a randomized placebo-controlled study. Clin Endocrinol. 2007;66:626-631.

18. Caine YG, Bauer KA, Barzegar S, et al. Coagulation activation following estrogen administration to postmenopausal women. Thromb Haemost. 1992;68:392-395.

19. Olié V, Plu-Bureau G, Conard J, et al. Menopause hormone therapy and recurrence of venous thromboembolism among postmenopausal women. Menopause. 2011;18:488-493.

20. Steingold KA, Laufer L, Chetkowski RJ, et al. Treatment of hot flashes with transdermal estradiol administration. J Clin Endocrinol Metab. 1985;61:627-632.

21. Climara ${ }^{\circledR}$ Prescribing Information. Whippany, NJ, USA: Bayer HealthCare Pharmaceuticals Inc.; Oct 2013. Available from: http:/ berlex.com/html/products/pi/Climara_PI.pdf. Accessed November 24, 2013.

22. Evamist ${ }^{\mathrm{TM}}$ Prescribing Information. St Louis, MO, USA: Ther-RX Corporation; 2013. Available from: http://www.evamist.com/pdf/ Evamist_PI.pdf. Accessed November 3, 2013.

23. Nachtigall LE. Emerging delivery systems for estrogen replacement: aspects of transdermal and oral delivery. Am J Obstet Gynecol. 1995;173(3 Pt 2):993-997.

24. Musel AL, Warshaw EM. Dermatitis cutaneous reactions to transdermal therapeutic systems. Dermatitis. 2006;17:109-122.

25. Samsioe G. Transdermal hormone therapy: gels and patches. Climacteric. 2004;7:347-356.

26. Kopper NW, Gudeman J, Thompson DJ. Transdermal hormone therapy in postmenopausal women: a review of metabolic effects and drug delivery technologies. Drug Des Devel Ther. 2008;2:193-202.

27. Wren B. Menorest: a clinical overview. Int J Gynaecol Obstet. 1996; 52 Suppl 1:S27-S29.

28. Hadgraft J, Lane ME. Passive transdermal drug delivery systems: recent considerations and advances. Am J Drug Deliv. 2006;4:153-160.

29. Akhila V, Pratapkumar. A comparison of transdermal and oral HRT for menopausal symptom control. Int J Fertil Womens Med. 2006;51 64-69.

30. Simon JA; ESTRASORB Study Group. Estradiol in micellar nanoparticles: the efficacy and safety of a novel transdermal drugdelivery technology in the management of moderate to severe vasomotor symptoms. Menopause. 2006;13:222-231.

31. Archer DF; EstroGel Study Group. Percutaneous 17beta-estradiol gel for the treatment of vasomotor symptoms in postmenopausal women. Menopause. 2003;10:516-221.

32. Hedrick RE, Ackerman RT, Koltun WD, Halvorsen MB. Estradiol gel $0.1 \%$ relieves vasomotor symptoms independent of age, ovarian status, or uterine status. Menopause. 2010;17:1167-1173.

33. Buster JE, Koltun WD, Pascual ML, Day WW, Peterson C. Low-dose estradiol spray to treat vasomotor symptoms: a randomized controlled trial. Obstet Gynecol. 2008;111:1343-1351.

34. Nelson HD. Commonly used types of postmenopausal estrogen for treatment of hot flashes: scientific review. JAMA. 2004;291:1610-1620.

35. Gordon SF, Thompson KA, Ruoff GE, Imig JR, Lane PJ, Schwenker CE; The Transdermal Estradiol Patch Study Group. Efficacy and safety of a seven-day, transdermal estradiol drug-delivery system: comparison with conjugated estrogens and placebo. Int J Fertil Menopausal Stud. 1995;40:126-134.

36. Bacchi-Modena A, Bolis P, Campagnoli C, et al. Efficacy and tolerability of Estraderm MX, a new estradiol matrix patch. Maturitas. 1997;27:285-292.
37. Wiklund I, Karlberg J, Mattsson LA. Quality of life of postmenopausal women on a regimen of transdermal estradiol therapy: a doubleblind placebo controlled study. Am J Obstet Gynecol. 1993;168: 824-830.

38. Speroff L, Whitcomb RW, Kempfert NJ, et al. Efficacy and local tolerance of a low-dose, 7-day matrix estradiol transdermal system in the treatment of menopausal vasomotor symptoms. Obstet Gynecol. 1996;88:587-592.

39. Utian WH, Burry KA, Archer DF, et al. Efficacy and safety of low, standard, and high dosages of an estradiol transdermal system (Esclim) compared with placebo on vasomotor symptoms in highly symptomatic menopausal patients. Am J Obstet Gynecol. 1999;181:71-79.

40. Good WR, John VA, Ramirez M, Higgins JE; Alora Study Group. Comparison of Alora estradiol matrix transdermal delivery system with oral conjugated equine estrogen therapy in relieving menopausal symptoms. Climacteric. 1999;2:29-36.

41. Studd JW, McCarthy K, Zamblera D, et al. Efficacy and tolerance of Menorest compared to Premarin in the treatment of postmenopausal women. Maturitas. 1995;22:105-114.

42. Notelovitz M, Cassel D, Hille D, et al. Efficacy of continuous sequential transdermal estradiol and norethindrone acetate in relieving vasomotor symptoms associated with menopause. Am J Obstet Gynecol. 2000;182: 7-12.

43. Shulman LP, Yankov V, Uhl K. Safety and efficacy of a continuous once-a-week 17beta-estradiol/levonorgestrel transdermal system and its effects on vasomotor symptoms and endometrial safety in postmenopausal women: the results of two multicenter, double-blind, randomized, controlled trials. Menopause. 2002;9:195-207.

44. von Holst T, Salbach B. Efficacy of a new 7-day transdermal sequential estradiol/levonorgestrel patch in women. Maturitas. 2002;41: 231-242.

45. Archer DF, Pickar JH, MacAllister DC, Warren MP. Transdermal estradiol gel for the treatment of symptomatic postmenopausal women. Menopause. 2012;19:622-629.

46. Hedrick RE, Ackerman RT, Koltun WD, Halvorsen MB, Lambrecht LJ. Transdermal estradiol gel $0.1 \%$ for the treatment of vasomotor symptoms in postmenopausal women. Menopause. 2009;16:132-140.

47. Hirvonen E, Crona N, Wahlström T, Bäckström AC. Effect of an estradiol gel with monthly or quarterly progestogen on menopausal symptoms and bleeding. Climacteric. 2000;3:262-270.

48. Mizunuma H. Clinical usefulness of a low-dose maintenance therapy with transdermal estradiol gel in Japanese women with estrogen deficiency symptoms. Climacteric. 2011;14:581-589.

49. Hirvonen E, Cacciatore B, Wahlström T, Rita H, Wilén-Rosenqvist G. Effects of transdermal oestrogen therapy in postmenopausal women: a comparative study of an oestradiol gel and an oestradiol delivering patch. Br J Obstet Gynaecol. 1997;104 Suppl 16:26-31.

50. Hirvonen E, Lamberg-Allardt C, Lankinen KS, Geurts P, WilénRosenqvist G. Transdermal oestradiol gel in the treatment of the climacterium: a comparison with oral therapy. Br J Obstet Gynaecol. 1997;104 Suppl 16:19-25.

51. Palacios S, Menendez C, Jurado AR, Vargas JC. Effects of percutaneous oestradiol versus oral oestrogens on bone density. Maturitas. 1994;20: 209-213.

52. Devogelaer JP, Lecart C, Dupret P, De Nayer P, Nagant De Deuxchaisnes C. Long-term effects of percutaneous estradiol on bone loss and bone metabolism in postmenopausal hysterectomized women. Maturitas. 1998;28:243-249.

53. Sun A, Lin S, Yu W, et al. Percutaneous estrogen in prevention of early postmenopausal bone loss in Chinese women. Chin Med J. 2002;115: $1790-1795$.

54. Blanc B, Cravello L, Micheletti MC, d'Ercole C, Zartarian M. Continuous hormone replacement therapy for menopause combining nomegestrol acetate and gel, patch, or oral estrogen: a comparison of amenorrhea rates. Clin Ther. 1998;20:901-912.

55. Anderson GL, Judd HL, Kaunitz AM, et al. Effects of estrogen plus progestin on gynecologic cancers and associated diagnostic procedures: the Women's Health Initiative randomized trial. JAMA. 2003;290: 1739-1748. 
56. Archer DF. The effect of the duration of progestin use on the occurrence of endometrial cancer in postmenopausal women. Menopause. 2001;8: 245-251.

57. Lethaby A, Farquhar C, Sarkis A, Roberts H, Jepson R, Barlow D. Hormone replacement therapy in postmenopausal women: endometrial hyperplasia and irregular bleeding. Cochrane Database Syst Rev. 2000;2:CD000402.

58. Naunton M, Al Hadithy AF, Brouwers JR, Archer DF. Estradiol gel: review of the pharmacology, pharmacokinetics, efficacy, and safety in menopausal women. Menopause. 2006;13:517-527.

59. Sacks F, Walsh B. Sex hormones and lipoprotein metabolism. Curr Opin Lipidol. 1994;5:236-240.

60. Hanggi W, Lippuner K, Riesen W, et al. Long term influence of different post-menopausal hormone replacement therapy on lipoprotein: a randomized study. Br J Obstet Gynaecol. 1997;104: 708-717.

61. Hulley S, Grady D, Bush T, et al. Randomized trial of estrogen plus progestin for secondary prevention of coronary heart disease in postmenopausal women. Heart and Estrogen/progestin Replacement Study (HERS) Research Group. JAMA. 1998;280:605-613.

62. Rossouw JE, Anderson GL, Prentice RL, et al. Risks and benefits of estrogen plus progestin in healthy postmenopausal women: principal results From the Women's Health Initiative randomized controlled trial. JAMA. 2002;288:321-333.
63. Adami S, Rossini M, Zamberlan N, Bertoldo F, Dorizzi R, Lo CV. Long-term effects of transdermal and oral estrogens on serum lipids and lipoproteins in postmenopausal women. Maturitas. 1993;17: 191-196.

64. Karjalainen A, Heikkinen J, Savolainen MJ, Backstrom AC, Salinto M, Kesaniemi YA. Metabolic changes induced by peroral oestrogen and transdermal oestradiol gel therapy. Br J Obstet Gynaecol. 1997; 104 Suppl 16:38-43.

65. Gomes MP, Deitcher SR. Risk of venous thromboembolic disease associated with hormonal contraceptives and hormone replacement therapy: a clinical review. Arch Intern Med. 2004;164:1965-1976.

66. Scarabin PY, Oger E, Plu-Bureau G, et al. Differential association of oral and transdermal oestrogen-replacement therapy with venous thromboembolism risk. Lancet. 2003;362:428-432.

67. Canonico M, Plu-Bureau G, Lowe GD, Scarabin PY. Hormone replacement therapy and the risk of venous thromboembolism in postmenopausal women: systematic review and meta-analysis. $B M J$. 2008;336:1227-1231.

68. Canonico M, Oger E, Plu-Bureau G, et al. Hormone therapy and venous thromboembolism among post-menopausal women. Impact of the route of estrogen administration and progestogens: the ESTHER Study. Circulation. 2008;115:840-845.
Research and Reports in Transdermal Drug Delivery

\section{Publish your work in this journal}

Research and Reports in Transdermal Drug Delivery is an international, peer-reviewed, open access online journal publishing original research, study protocols, reviews, editorials and commentaries on all aspects of transdermal drug delivery. Specific topics in the journal include: Laboratory and clinical development of drug delivery systems including preclinical, clinical studies and protocols; Rationale and basic science; Drug

\section{Dovepress}

delivery via gels, creams or patches; Use of chemical drug penetration enhancers Patient acceptability studies; and pharmacoeconomic and clinical outcome studies. The manuscript management system is completely online and includes a very quick and fair peer-review system, which is all easy to use. Visit http://www.dovepress.com/ testimonials.php to read real quotes from published authors. 